\title{
RESISTANCE OF THERMALLY SPRAYED COATINGS IN AN ENVIRONMENT SIMULATING A TURBINE OF GEOTERMAL POWER PLANT
}

\author{
1'Šárka HOUDKOVÁ, ${ }^{2}$ Marek VOSTŘÁK, ${ }^{3}$ Kateřina LENCOVÁ, ${ }^{4}$ Petra ŠULCOVÁ, ${ }^{5} J o s e f$ \\ DULIŠKOVIČ \\ Research and Testing Institute Plzen, Plzeň, Czech Republic, EU, \\ 1houdova@vzuplzen.cz, ${ }^{2}$ vostrak@vzuplzen.cz, ${ }^{3}$ lencova@vzuplzen.cz, ${ }^{4}$ sulcova@vzuplzen.cz, \\ 50duliskovic@vzuplzen.cz
}

https://doi.org/10.37904/metal.2021.4188

\begin{abstract}
The paper focuses on the evaluation of the ability of selected heat sprayed coatings to protect the surface of the component in an environment simulating the environment of a geothermal turbine. The subject of testing were coatings based on hardmetals, applied by HVOF technology (WC-CoCr, $\mathrm{Cr}_{3} \mathrm{C}_{2}-\mathrm{NiCr}$ ) and $\mathrm{Fe}$ and $\mathrm{Ni}$ based alloys, applied by HVOF ( $\mathrm{NiCr}$, FeCrAIY) and TWAS (FeCrAINiC, FeCr, NiCr) technologies. It has been shown that although HVOF coatings provide higher protective properties in terms of both corrosion and resistance to mechanical influences, it is also possible to apply the protective coating with TWAS technology if mobile spraying is required. From the materials tested, the Fe-based Metco 8294 can be recommended as a most promising, providing high wear resistance and sufficient corrosion resistance in aggressive environment.
\end{abstract}

Keywords: Thermal spray, coating, corrosion, erosion, power, geothermal

\section{INTRODUCTION}

Thermal spraying technologies represent a fast-growing part of surface treatment and advanced materials. Thermally sprayed coatings are generally applied mainly to increase the service life of coated components, to achieve specific functional properties or to renovate damaged surfaces. One of the many areas that can use the potential of thermal spraying technology is the field of energy, e.g., to increase the life and efficiency of steam, combustion and geothermal power plants turbines. Materials intended for the production of geothermal turbine components are highly stressed, especially in terms of corrosive substances. Steam in geothermal turbines contains high amounts of chlorides, sulfates, carbon oxides and others. Although most of their amount is removed by separators before entering the turbine, the remaining amount in steam significantly exceeds the amount present in the steam of fossil fuel turbines. In addition to the corrosion protection, the applied coatings are also expected to extend the service life of the components by increasing their wear resistance. For those purposes, the HVOF (High Velocity Oxygen Fuel) or HVAF (High Velocity Air Fuel) sprayed hardmetals [1] are usually considered to bet the best choice. On the other hand, there exist growing number of wear and corrosion resistant materials in the form of a wire, enabling application using mobile and less expensive TWAS (Twin Wire Arc Spraying) technology. The aim of this paper is to compare the potential of selected TWAS coatings to be applied in the environment of geothermal turbine, and compare their performance to the HVOF sprayed materials. Both wear resistance and ability of the coatings protect the surface from corrosion was the subject of evaluation. 


\section{EXPERIMENTAL}

\subsection{Specimens preparation}

The testing samples were sprayed applying different deposition technologies: TWAS SmartArc Oerlicon Metco spraying system and HP/HVOF Praxiar TAFA JP5000 spraying system. The coatings nominal composition, together with the deposition technology used, are summarized in the Table 1. The deposition parameters were previously optimized for each coating material to obtain expected microstructures, without cracks or excessive porosity. The material of substrate was common carbon steel (ČSN 11523), the substrate surface was cleaned and grit blasted prior to the spraying $\left(\mathrm{Al}_{2} \mathrm{O}_{3} ; \mathrm{F} 22\right)$ to reach desired surface roughness, enabling sufficient adhesion of deposited coatings.

Table 1 Deposited coatings materials

\begin{tabular}{|c|c|c|c|}
\hline Coating no. & Trade mark & $\begin{array}{c}\text { Nominal composition } \\
(\mathbf{w t} \%)\end{array}$ & $\begin{array}{c}\text { Average coating thickness } \\
(\boldsymbol{\mu} \text { m })\end{array}$ \\
\hline TWAS 1 & Metco 8450 & $\mathrm{Cr} 20 \%, \mathrm{Ni}$ bal & $545 \pm 9$ \\
\hline TWAS 2 & Metco 8294 & $\begin{array}{c}\text { Cr 18,09\%, Ni 17,9\%, C 4,62\%, Al 2,06\%, } \\
\text { V 2\%, Si 0,25\%, Fe bal }\end{array}$ & 53740 \\
\hline TWAS 3 & W504.1 & Cr 13\%, Fe bal & $439 \pm 10$ \\
\hline HVOF 1 & Amdry 9700 & Cr 24\%, Al 8\%, 0,5 \% Y, Fe bal & $369 \pm 30$ \\
\hline HVOF 2 & Amdry 4535 & Cr 20\%. Ni bal & $348 \pm 8$ \\
\hline HVOF 3 & WOKA 3652 & Co 10\%, Cr 4\%, WC bal & $429 \pm 9$ \\
\hline HVOF 4 & Amperit 588.074 & C 10\%, Ni 15\%, Cr bal & $470 \pm 11$ \\
\hline
\end{tabular}

The size of the samples was design in accordance of each test requirements. For microstructure, hardness and wear testing, the coating was deposited on the upper surface of the samples. For evaluation of coatings ability to protect the substrate from the environment of geothermal turbine, the disk samples $(\varnothing 25 \mathrm{~mm}, 5 \mathrm{~mm}$ thickness) were designed and sprayed to cover all its surface. Subsequently, one surface was gently ground to remove the coatings surface roughness, while the other was used for laser marking to avoid confusion of samples after the test (Figure 1).
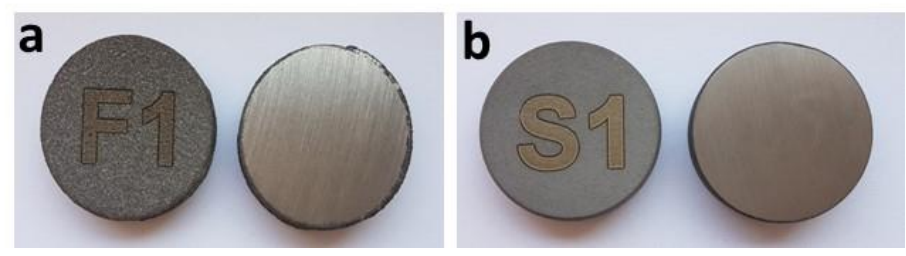

Figure 1 Examples of coated sample, ready for geothermal environment corrosion testing:

a) TWAS 1 - NiCr; b) HVOF 4 - $\mathrm{Cr}_{2} \mathrm{C}_{3}-\mathrm{NiCr}$

\subsection{Testing procedures}

The coatings microstructure was evaluated in the coatings' cross sections, grinded and polished by standard metallographic procedure. The optical microscopy (OM) was used to measure the coating thickness and to evaluate their microstructure. The Vickers microhardness HV0.3 was measured in the coatings' cross sections. At least 7 indents were made and the average value is reported. The abrasive wear resistance was measured using the Dry sand/Rubber Wheel test in accordance to ASTM G-65. For each coating, three tests were realized, the average value is reported. After the wear tests, the wear mechanism was analysed by SEM. The 
solid particle erosion was tested using centrifugal erosion test. The impact angle of erosive media $\left(\mathrm{Al}_{2} \mathrm{O}_{3} ; \mathrm{F} 70\right)$ varied between $15^{\circ}-90^{\circ}$. After the test, the wear mechanism was analysed by SEM.

The ability to protect substrate surface from the aggressive environment of geothermal turbine was tested in the autoclave, designed and operated in MATERIÁLOVÝ A METALURGICKÝ VÝZKUM s.r.o. (The MATERIAL AND METALLURGICAL RESEARCH Co., Ltd., hereinafter referred to as MMV). The used autoclave is shown in the Figure 2. The required conditions of test are summarized in Table 2. After testing, the samples were cut and evaluated by OM and SEM, to reveal the potential corrosion of coatings and underlying substrate.
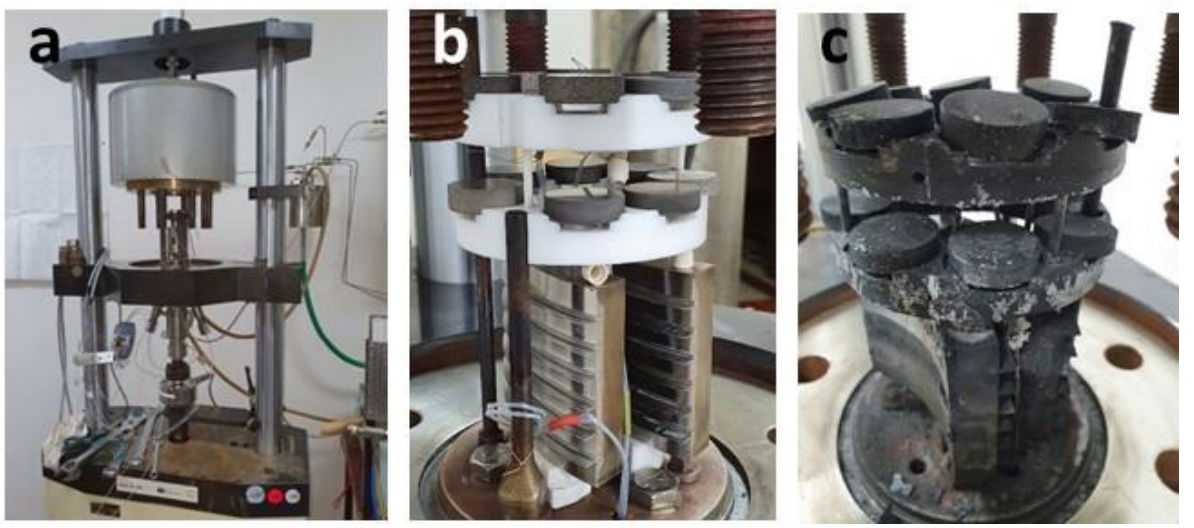

Figure 2 The testing autoclave: a) overall view; b) samples prior test; c) samples after test

Table 2 Composition of used water solution and testing conditions

\begin{tabular}{|c|c|c|c|c|c|c|c|}
\hline $\mathrm{Cl}^{-}$ & $\mathbf{S O}_{4}$ & $\mathbf{C O}_{2}$ & $\mathbf{H}_{2} \mathbf{S}$ & $\mathbf{p H}$ & Temperature & Preassure & Time of exposition \\
\hline $10000 \mathrm{ppm}$ & $50 \mathrm{ppm}$ & $3000 \mathrm{ppm}$ & $300 \mathrm{ppm}$ & $3.5-4$ & $250 \sim \mathrm{C}$ & $12 \mathrm{bar}$ & 105 days \\
\hline
\end{tabular}

\section{RESULTS AND DISSCUSION}

The microstructure of sprayed coatings contains the features typical for used deposition technique. As it can be seen from the cross sections, the porosity, as well as the quality of bonding differs significantly between TWAS and HVOF sprayed coatings. The higher porosity, as well as the bonding between individual splats, and between the coating and substrate, are the main factors influencing the ability of the coating to protect the substrate from the surrounding environment.

Table 3 Measured coatings superficial hardness and cross section microhardness

\begin{tabular}{|c|c|c|c|c|c|c|c|}
\hline Coating & TWAS 1 & TWAS 2 & TWAS 3 & HVOF 1 & HVOF 2 & HVOF 3 & HVOF 4 \\
\hline HR 15N & $62.8 \pm 1$ & $64.0 \pm 4.6$ & $77.7 \pm 0.9$ & $74.1 \pm 2.1$ & $74.0 \pm 1.3$ & $88.1 \pm 0.9$ & $96.4 \pm 0.4$ \\
\hline HV 0.3 & $232 \pm 34$ & $496 \pm 47$ & $469 \pm 53$ & $393 \pm 29$ & $301 \pm 20$ & $1134 \pm 95$ & $978 \pm 72$ \\
\hline
\end{tabular}

The surface hardness value reflects both - the influence of coating material, as well as the amount of coating porosity, while cross section microhardness represents mainly the properties of coating the materials. That is why the trend of HR $15 \mathrm{~N}$ and HV 0.3 values is not similar (Table 3 ). The most significant difference is between HVOF 3 (WC-14\%CoCr) and HVOF $4\left(\mathrm{Cr}_{3} \mathrm{C}_{2}-25 \% \mathrm{NiCr}\right)$ coatings. The HVOF 3 coating contains higher amount of porosity compare to HVOF 4 (see Figure 3), leading to lower HR15N value. On the other hand, the higher amount of soft NiCr matrix is responsible for lower HV0.3 value of HVOF 4. The influence of used spraying technology can be seen from the difference between the hardness values of TWAS 1 and HVOF 2 coating, consisting both from $\mathrm{Ni} 20 \% \mathrm{Cr}$ material. 

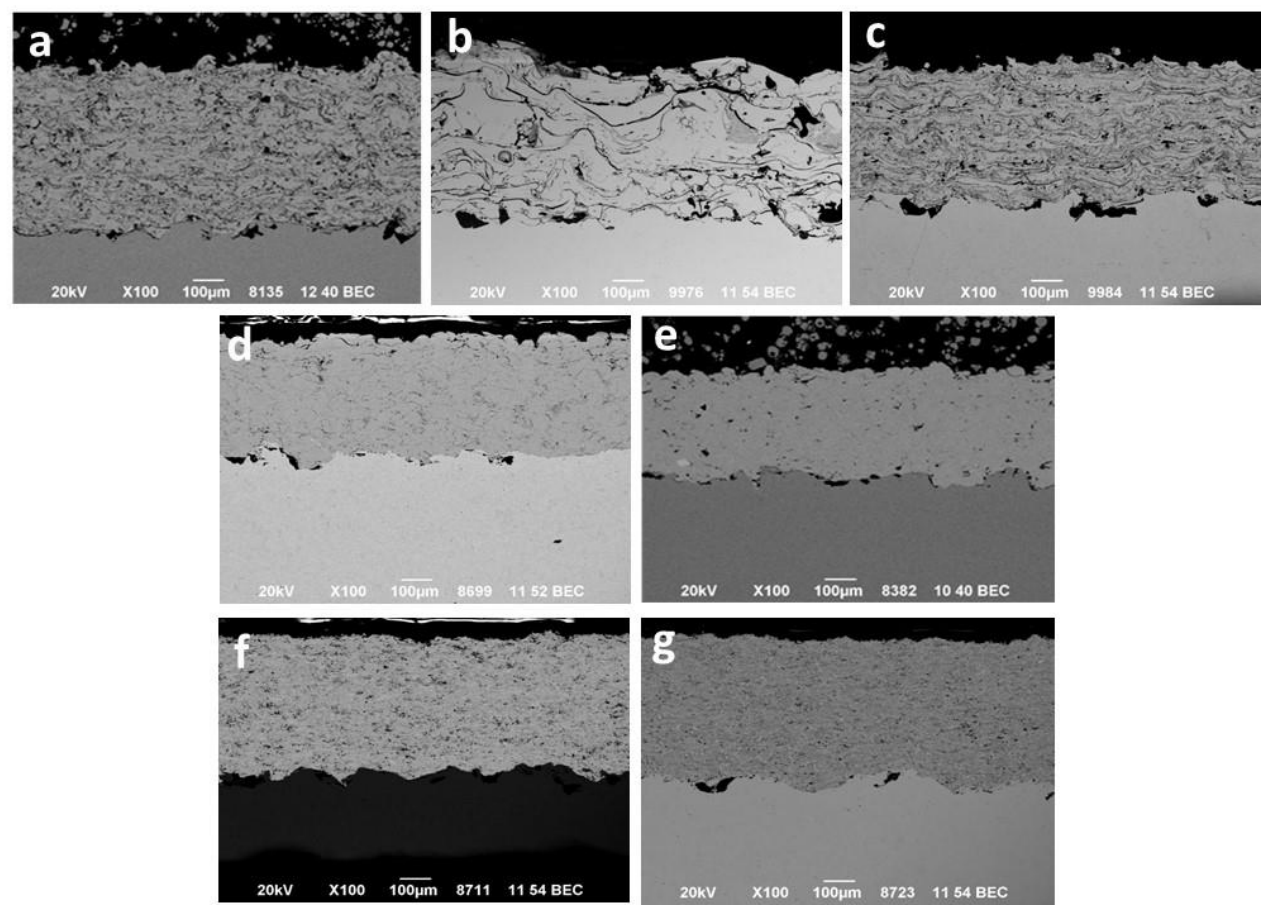

Figure 3 The coatings cross sections: a) TWAS 1; b) TWAS 2; c) TWAS 3; d) HVOF 1; e) HVOF 2; f) HVOF $3 ;$ g) HVOF 4

As expected, the abrasion wear resistance (Figure 4a) is in general agreement with the coating microhardness. The only exception is in the case of TWAS $3(\mathrm{Fe} 13 \% \mathrm{Cr})$, where higher wear abrasive wear resistance was expected based on the microhardness values. However, the high microhradness was probably achieved by higher number of inner oxides, originated on the surface of molten particle during spraying. The oxides can be also responsible for high coatings volume loss during solid particle erosion test (Figure $\mathbf{4 b}$ ). Generally speaking, the HVOF hardmetal coatings shown superior performance compared to TWAS coatings.
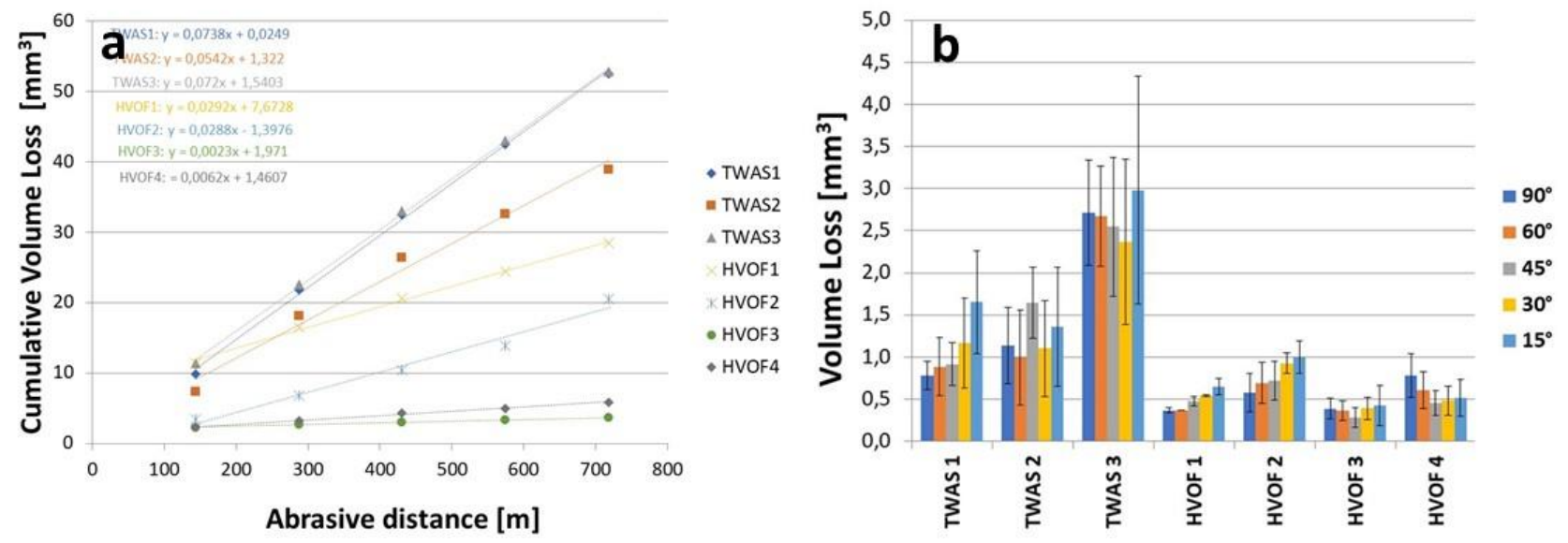

Figure 4 Coatings wear resistance: a) Dry Sand/Rubber Wheel test results; b) Centrifugal Solid Particle Erosion test result

The example of long-term exposition test results in environment, simulating the environment of geothermal power plant turbine, can be seen in the (Figure 5). The surface off all samples was covered by thin layer of oxides. No massive oxidation or coatings spallation due to the corrosion of coating or underlaying substrate was recorded. However, the examination of coatings cross section reveled the signs of corrosion not only on 
the coatings surface, but also on the intersplat boundaries and on the surface of underling substrate, namely in case of TWAS coatings (Figure 6). The most developed damage was observed for TWAS $3-\mathrm{Fe} 13 \% \mathrm{Cr}$ coating, where not only substrate, but also coating material itself suffers from corrosion.
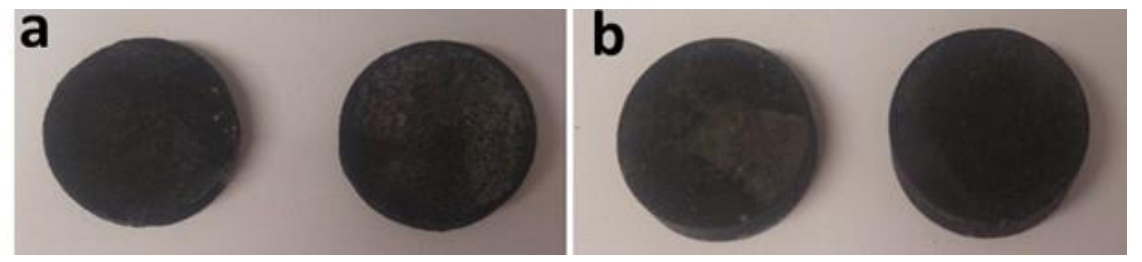

Figure 5 Examples of coated sample, after 3 months of exposition in autoclave: a) TWAS 1 - NiCr;

b) $\mathrm{HVOF} 4-\mathrm{Cr}_{2} \mathrm{C}_{3}-\mathrm{NiCr}$
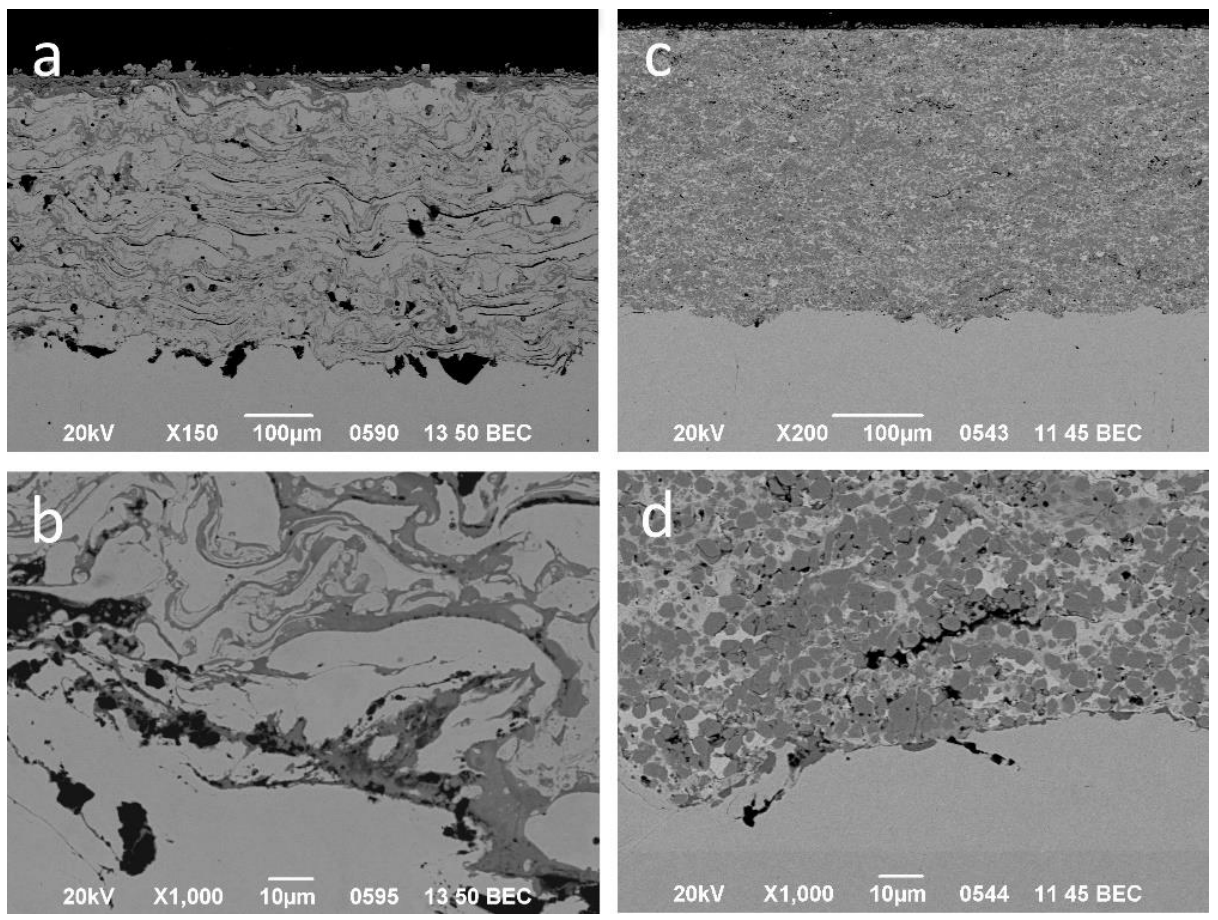

Figure 6 Cross-sectional backscattered SEM micrograph of the corroded coated samples: a, b) TWAS3 -

$\mathrm{Fe} 13 \% \mathrm{Cr} ; \mathrm{c}, \mathrm{d}) \mathrm{HVOF} 4-\mathrm{Cr}_{2} \mathrm{C}_{3}-\mathrm{NiCr}$

Figure 6 illustrates the SEM backscattered electron micrograph of the cross-sectional surface of the tested coatings 3 months of exposition in the autoclave. In all cases, corrosion of the substrate was observed in small amounts. At the interface between the coating and the substrate, the corrosion mechanism was similar to crevice corrosion. Pitting corrosion has been observed in some places on the surface of the substrate. In many cases, corrosion pits were observed near $\mathrm{Al}_{2} \mathrm{O}_{3}$ particles trapped in the substrate. $\mathrm{Al}_{2} \mathrm{O}_{3}$ particles break the passivation layer and deform the grains near the substrate surface during blasting. The corrosion attack then proceeds along the grain boundaries of the substrate by the mechanism of intergranular corrosion. In the case of TWAS3, corrosion attack was also observed in the microstructure of the coating (Figure $6 \mathbf{b}$ ). Corrosion products grew in the space between the individual splats and on the surface of the pores. In the case of TWAS3, corrosion was initiated preferentially at the splat boundaries, probably due to a microscopic corrosion mechanism. This form of corrosion has been reported in previous works, or the literature by different authors $[2,3]$. On the contrary, as expected, the slightest corrosion attack was observed in the case of $\mathrm{HVOF}_{4}\left(\mathrm{Cr}_{2} \mathrm{C}_{3}-\right.$ $\mathrm{NiCr}$ ). This behavior is related to the low porosity of the coatings. High porosity has a deleterious effect on corrosion resistance. On a sample of HVOF4, no corrosion was observed in the microstructure of the coating 
or at the interface between the coating and the substrate. Only in some places did corrosion occur between the grain boundaries near the surface of the substrate [4]. The morphological evidence provided by SEM analysis supports the fact that there are mainly two corrosion processes at the interface between the substrate and the coating. Namely, crevice corrosion and pitting corrosion. The corrosion then continues to attack the substrate by an intergranular corrosion mechanism. The amount of corrosion attack is determined primarily by the porosity of the coating and thus the amount of corrosion medium that is able to transport to the surface of the substrate.

\section{CONCLUSION}

The TWAS sprayed coating had generally lower wear and corrosion resistance. From the materials tested, the most promising results was reached by Fe-based alloy with high chromium and nickel content (TWAS 2). From the group of HVOF coating materials, the wear resistance results match the expectations - the hardmetals are more wear resistant than alloys. The corrosion resistance in the environment simulating the geothermal turbine of was fond to be dependent mostly on the porosity of the coating - the less porous hardmetal coatings protect the substrate the best, however some hints of corrosion attack was identified in all tested samples. The coating materials themselves, with the exception of $\mathrm{Fe}-13 \% \mathrm{Cr}$ (TWAS 3), were resistant to the environment. From the point of view of the development of corrosion attack, the areas around the built-in $\mathrm{Al}_{2} \mathrm{O}_{3}$ particles, built into the substrate after blasting, proved to be a critical point.

\section{ACKNOWLEDGEMENTS}

\section{The paper was prepared due to institutional support for the long-time conception development of the research institution provided by the Ministry of Industry and Trade of the Czech Republic to Research and Testing Institute Plzeň.}

\section{REFERENCES}

[1] BOLELLI, L., BERGER, L.-M., BÖRNER, T, KOIVULUOTO, H., LUSVARGHI, L., LYPHOUT, C., MARKOCSAN, N., MATIKAINEN, V., NYLÉN, P., SASSATELLI, P., TRACHE, R., VUORISTO, P. Tribology of HVOF- and HVAFsprayed WC-10CO4Cr hardmetal coatings: a comparative assessment. Surface \& Coatings Technology. [online]. 2015, vol 265, pp 125-144, Available from: https://doi.org/10.1016/i.surfcoat.2015.01.048.

[2] SHRESTHA, S., HODGKIESS, T. NEVILLE, A. The effect of post-treatment of a high-velocity oxy-fuel Ni-Cr-MoSi-B coating Part I: Microstructure/corrosion behavior relationships. Journal of Thermal Spray Technology. 2001, vol 10, no. 3, pp 470-479.

[3] ASHARY, A.A., TUCKER, R.C. Corrosion characteristics of several thermal spray cermet-coating/alloy systems. In: Metallurgical Coatings and Thin Films. 1991, pp. 78-82. ISBN 9780444894557,

[4] GIL, L., STAIA, M.H. Influence of HVOF parameters on the corrosion resistance of NiWCrBSi coatings. Thin Solid Films. 2002, vol 420-421, pp 446-454. 